\title{
Oxidative stress induces proliferation of colorectal cancer cells by inhibiting RUNX3 and activating the Akt signaling pathway
}

\author{
KYOUNG AH KANG $^{1}$, KI CHEON KIM $^{1}$, SUK CHUL BAE $^{2}$ and JIN WON HYUN ${ }^{1}$ \\ ${ }^{1}$ School of Medicine, and Institute for Nuclear Science and Technology, Jeju National University, Jeju 690-756; \\ ${ }^{2}$ Department of Biochemistry, School of Medicine, and Institute for Tumor Research, \\ Chungbuk National University, Cheongju 361-763, Republic of Korea
}

Received June 21,2013; Accepted August 2, 2013

DOI: $10.3892 /$ ijo.2013.2102

\begin{abstract}
We recently reported that the tumor suppressor Runt-related transcription factor 3 (RUNX3) is silenced in colorectal cancer cells via oxidative stress-induced hypermethylation of its promoter. The resulting downregulation of RUNX3 expression influences cell proliferation. Activation of the Akt signaling pathway is also associated with cell survival and proliferation; however, the effects of oxidative stress on the relationship between RUNX3 and Akt signaling are largely unknown. Therefore, this study investigated the mechanisms involved in cell proliferation caused by oxidative stress-induced silencing of RUNX3. The levels of RUNX3 mRNA and protein were downregulated in response to treatment of the human colorectal cancer cell line SNU-407 with $\mathrm{H}_{2} \mathrm{O}_{2}$. Treatment of the cells with $\mathrm{H}_{2} \mathrm{O}_{2}$ also upregulated Akt mRNA and protein expression, and inhibited the binding of RUNX3 to the Akt promoter. The inverse correlation between the expression levels of RUNX3 and Akt in $\mathrm{H}_{2} \mathrm{O}_{2}$ treated cells was also associated with nuclear translocation of $\beta$-catenin and upregulation of cyclin D1 expression, which induced cell proliferation. $\mathrm{H}_{2} \mathrm{O}_{2}$ treatment also increased the binding of $\beta$-catenin to the cyclin D1 promoter. The results presented here demonstrate that reactive oxygen species silence the tumor suppressor RUNX3, enhance the Akt-mediated signaling pathway, and promote the proliferation of colorectal cancer cells.
\end{abstract}

\section{Introduction}

Reactive oxygen species (ROS) are mutagenic and hence may promote cancer (1). ROS modulate growth signals and regulate gene expression, leading to the sustained proliferation of cancer cells (2). Oxidative stress caused by metabolic, dietary,

Correspondence to: Professor Jin Won Hyun, School of Medicine, Jeju National University, Jeju 690-756, Republic of Korea

E-mail: jinwonh@jejunu.ac.kr

Key words: runt-related transcription factor 3, tumor suppressor gene, colorectal cancer, reactive oxygen species, Akt, $\beta$-catenin, cyclin D1, cell proliferation and environmental factors leads to excessive production of ROS, which can then induce genetic alterations, including frameshift mutations in tumor suppressor genes $(3,4)$ such as the type II transforming growth factor- $\beta$ (TGF- $\beta$ ) receptor (5). These mutations may allow colon epithelial cells to escape growth restriction mediated by ligation of TGF- $\beta$ to its type II receptor.

In addition to genetic alterations, epigenetic changes also result in the loss of or aberrant expression of genes associated with carcinogenesis (6). ROS trigger DNA methylation of tumor suppressor gene promoters; Lim et al have suggested a functional pathway model of ROS-induced epigenetic changes in which persistently elevated levels of ROS induce $\mathrm{CpG}$ methylation in the promoter region of the gene encoding the tumor suppressor E-cadherin, via specific recognition of an E-box motif by Snail (7). In addition, the tumor suppressor Runt-related transcription factor 3 (RUNX3) is silenced by ROS-induced epigenetic regulation in colorectal cancer cells (8).

Akt signaling upregulates the Wnt signaling pathway via inhibitory phosphorylation of glycogen synthase kinase- $3 \beta$ (GSK-3 $\beta)$, which results in stabilization of $\beta$-catenin and its relocation from the cell membrane to the nucleus, where it is recruited into $\mathrm{TCF} / \mathrm{LEF}$ transcriptional regulatory complexes (9-11). TCF/LEF complexes bind to enhancer regions of target genes involved in proliferation, invasion, and inhibition of apoptosis, including c-Myc and cyclin D1. These effects contribute directly to colon cancer development.

RUNX3 is a tumor suppressor that is involved in various cancers, including gastric cancer $(12,13)$. RUNX3 knockout mice exhibit gastric epithelial hyperplasia, reduced levels of apoptosis, and reduced sensitivity to TGF- $\beta$ (14). Approximately 45-60\% of human gastric cancers display a loss of RUNX3 expression due to hemizygous deletion and promoter hypermethylation (14). By interacting with Smad2/3, Smad4, p300, and FoxO3a to regulate the transcription of target genes, RUNX3 is involved in the TGF- $\beta$-mediated signaling pathway (15). RUNX3 suppresses gastric tumorigenesis by upregulating p21 (16), Bim (17), and Claudin-1 (18). The gastrointestinal tract, particularly the colon and rectum, is constantly exposed to ROS originating from endogenous and exogenous sources (19). The involvement of ROS in colorectal cancer remains speculative; however, numerous epidemio- 
logical studies suggest that oxidative stress is an important factor in cancer initiation and progression $(13,20,21)$.

We recently reported that oxidative stress downregulates RUNX3 expression by upregulating DNA methyltransferase 1 and histone deacetylase, resulting in hypermethylation of the RUNX3 promoter (8). In this study, we investigated whether oxidative stress is able to regulate the Akt signaling pathway by reducing the expression of the RUNX3 tumor suppressor in colorectal cancer cells.

\section{Materials and methods}

Cell culture. The human colorectal cancer cell line SNU-407 (Korean Cell Line Bank, Seoul, Republic of Korea) was maintained at $37^{\circ} \mathrm{C}$ in a humidified atmosphere of $5 \% \mathrm{CO}_{2}$. The cells were cultured in RPMI-1640 medium containing $10 \%$ fetal calf serum, streptomycin $(100 \mu \mathrm{g} / \mathrm{ml})$, and penicillin (100 U/ml).

Western blot analysis. Nuclear extracts were prepared using a Nuclear Protein Extraction kit (Cayman Chemical, Ann Arbor, MI, USA). The nuclear extracts were lysed on ice for $4 \mathrm{~min}$ in $1 \mathrm{ml}$ of lysis buffer comprising $10 \mathrm{mM}$ Tris- $\mathrm{HCl}$ (pH 7.9), $10 \mathrm{mM} \mathrm{NaCl}, 3 \mathrm{mM} \mathrm{MgCl}_{2}$, and $1 \%$ NP-40. After centrifugation for $10 \mathrm{~min}$ at $3000 \mathrm{x} \mathrm{g}$, the pellets were re-suspended in $50 \mu \mathrm{l}$ of extraction buffer (20 mM HEPES, pH 7.9, 20\% glycerol, $1.5 \mathrm{mM} \mathrm{MgCl}_{2}$, $0.2 \mathrm{mM}$ EDTA, $1 \mathrm{mM}$ DTT, and $1 \mathrm{mM}$ PMSF), incubated on ice for $30 \mathrm{~min}$, and then centrifuged at $13000 \mathrm{x} \mathrm{g}$ for $5 \mathrm{~min}$. After determination of the protein concentration, the supernatants were stored at $-70^{\circ} \mathrm{C}$. Aliquots of the lysates (40 $\mu \mathrm{g}$ of protein) were boiled for $5 \mathrm{~min}$ and then electrophoresed on a $10 \%$ SDS-polyacrylamide gel. Blots of the gels were transferred to nitrocellulose membranes, which were subsequently incubated with primary antibodies and then with secondary immunoglobulin-G horseradish peroxidase conjugates (Pierce, Rockford, IL, USA). The protein bands were detected using an enhanced chemiluminescence western blotting detection kit (Amersham, Little Chalfont, Buckinghamshire, UK) and were visualized using a luminescent image analyzer.

Immunocytochemistry. Cells plated on coverslips were fixed in $4 \%$ paraformaldehyde for $30 \mathrm{~min}$ and then permeabilized with PBS containing $0.1 \%$ Triton X-100 for $2.5 \mathrm{~min}$. Cells were treated with blocking medium (PBS containing 3\% bovine serum albumin) for $1 \mathrm{~h}$ and incubated with an antiRUNX3 antibody diluted in blocking medium for $2 \mathrm{~h}$. The primary anti-RUNX3 antibody was detected by incubation with a 1:500 dilution of the FITC-conjugated secondary antibody (Santa Cruz Biotechnology, Santa Cruz, CA, USA) for $1 \mathrm{~h}$. After washing with PBS, the stained cells were mounted onto microscope slides in mounting medium containing DAPI (Vector, Burlingame, CA, USA). Images were collected using the LSM 510 program on a Zeiss confocal microscope.

Trypan blue staining. Trypan blue solution (0.4\%) was added to the cell suspension at a 1:5 ratio and the suspension was incubated at room temperature for $5 \mathrm{~min}$. Viable cells that did not show any staining were counted under a microscope using a hemocytometer.

RNA isolation and reverse transcription-PCR (RT-PCR). Total RNA was isolated from cells using Trizol reagent (GibcoBRL, Grand Island, NY, USA) and the cDNA was amplified using $1 \mu \mathrm{l}$ of reverse transcription reaction buffer, primers, dNTPs, and $0.5 \mathrm{U}$ of Taq DNA polymerase in a final volume of $25 \mu \mathrm{l}$, as described previously (22). The PCR conditions were as follows: initial denaturation at $94^{\circ} \mathrm{C}$ for $5 \mathrm{~min}$, followed by 35 cycles of $94^{\circ} \mathrm{C}$ for $1 \mathrm{~min}, 55^{\circ} \mathrm{C}$ for $1 \mathrm{~min}$, and $72^{\circ} \mathrm{C}$ for $1 \mathrm{~min}$, and then a final elongation step at $72^{\circ} \mathrm{C}$ for $7 \mathrm{~min}$. The following primers were used to amplify human RUNX3 and Akt: RUNX3 sense, 5'-GGCAATGACGAGA ACTAC-3' (located in exon 2); RUNX3 antisense, 5'-GGAGAATGGGTTCAGTTC-3' (located in exon 5); Akt sense, 5'-GCAGCACGTGTACGAGAAGA-3'; and Akt antisense, 5'-GGTGTCAGTCTCCGACGTG-3'. The amplified products were resolved by $1 \%$ agarose gel electrophoresis, stained with ethidium bromide, and then photographed under UV light using Image Quant ${ }^{\mathrm{TM}} \mathrm{TL}$ analysis software (Amersham Bioscience, Sweden).

Transient transfection of small interfering RNA (siRNA). Cells were seeded into 24 -well plates at a density of $1.5 \times 10^{5}$ cells/ well and allowed to reach approximately $50 \%$ confluency. Cells were then transfected with 10-50 nM of a mismatched siRNA control (siControl; Santa Cruz Biotechnology) or an siRNA targeted against RUNX3 (Santa Cruz Biotechnology) using Lipofectamine RNAiMax reagent (Invitrogen, Carlsbad, CA, USA), according to the manufacturer's instructions. Twenty-four hours after transfection, the cells were treated with 5-fluorouracil for a further $48 \mathrm{~h}$ and then examined using an MTT assay.

Chromatin immunoprecipitation (ChIP) assay. The ChIP assay was performed using the SimpleChIP ${ }^{\text {тм }}$ enzymatic chromatin IP kit (Cell Signaling Technology, Danvers, MA, USA) according to the manufacturer's protocol with slight modifications. Briefly, cells were pre-treated with $1 \mathrm{mM}$ $\mathrm{N}$-acetyl cysteine for $1 \mathrm{~h}$, treated with $\mathrm{H}_{2} \mathrm{O}_{2}$ for $48 \mathrm{~h}$, and then cross-linked by the addition of $1 \%$ formaldehyde. Chromatin was prepared and digested with nuclease for $12 \mathrm{~min}$ at $37^{\circ} \mathrm{C}$. The ChIP assay was performed using a DNMT1 antibody (Abcam, Cambridge, MA, USA) and normal rabbit IgG. The antibodies were added to the chromatin digests and the mixtures were incubated overnight at $4^{\circ} \mathrm{C}$ with constant rotation. ChIPgrade protein $\mathrm{G}$ magnetic beads were added to capture the immunoprecipitated complexes. The beads were washed and the immunoprecipitates were eluted with ChIP elution buffer. The cross-links were reversed by incubation at $65^{\circ} \mathrm{C}$ for $30 \mathrm{~min}$ and then proteinase $\mathrm{K}$ was added and the samples were incubated for a further $2 \mathrm{~h}$ at $65^{\circ} \mathrm{C}$. The immunoprecipitated DNA fragments were purified using spin columns and the DNA recovered from the immunoprecipitated complexes was subjected to 35 cycles of PCR amplification. The primers used to amplify the DNA fragment were as follows (23): RUNX3 binding site 1 (RBS1) sense, 5'-TTTCCATCCTGCTAAGT ACTT-3'; RBS1 antisense, 5'-GATCCCAACATGGGTC TTTCC-3'; RBS2 sense, 5'-ACTTGTCTGAACCTCTC 
TTTG-3'; RBS2 antisense, 5'-AAAGCAAAGAAATTC AAACAT-3'; catenin binding site sense, 5'-GAGCGCATGCT AAGCTGAAA-3'; and catenin binding site antisense, 5'-GGA CAGACGGCCAAAGAATC-3'. The PCR products were separated on $2 \%$ agarose gels and the DNA bands were visualized using the Image program (NIH, Bethesda, MD, USA).

Statistical analysis. All measurements were performed in triplicate and all data are represented as the mean \pm SEM. The results were subjected to an analysis of variance using Tukey's test. $\mathrm{P}<0.05$ was considered statistically significant.

\section{Results}

ROS downregulate RUNX3 expression and upregulate Akt expression in $S N U-407$ cells. In a previous study, we demonstrated that oxidative stress attenuates RUNX3 expression in human colorectal cancer SNU-407 cells (8). To confirm this finding, SNU-407 cells were treated with $100 \mu \mathrm{M}$ $\mathrm{H}_{2} \mathrm{O}_{2}$ for $48 \mathrm{~h}$ and a significant decrease in nuclear RUNX3 protein levels were detected by immunoblot and confocal imaging analyses (Figs. 1A and 1B). In addition, growth of the SNU-407 cells was significantly increased by the $\mathrm{H}_{2} \mathrm{O}_{2}$ treatment (Fig. 1C). These results suggest that RUNX3 has a negative influence on the proliferation of SNU-407 cells. RUNX3 represses Akt1 expression through transcriptional inhibition and the loss of RUNX3 promotes tumorigenesis via activation of the Akt1/ $\beta$-catenin/cyclin D1 signaling pathway (23). In agreement with these findings, immunoblot analyses revealed that treatment of SNU-407 cells with $\mathrm{H}_{2} \mathrm{O}_{2}$ resulted in substantial increases in total Akt and phosphorylated Akt protein levels (Fig. 1D).

ROS reverse RUNX3-mediated repression of Akt transcription. Next, to investigate the inverse correlation between RUNX3 and Akt expression, a siRNA was used to knockdown endogenous RUNX3 in SNU-407 cells, which express high levels of the tumor suppressor. Total and phosphorylated Akt protein levels were higher in cells treated with a RUNX3specific siRNA than in cells treated with a control siRNA (Fig. 2). The inverse correlation between RUNX3 and Akt expression was further confirmed by RT-PCR. Cells treated with $\mathrm{H}_{2} \mathrm{O}_{2}$ for up to $48 \mathrm{~h}$ showed a time-dependent decrease in the level of RUNX3 mRNA and a parallel increase in the level of Akt mRNA (Fig. 3A). Two RUNX3-binding sites (RBS1 and RBS2) with the consensus sequence 'TGTGGT' are present in the Akt1 promoter region. A ChIP assay revealed that, compared with control cells, those treated with $\mathrm{H}_{2} \mathrm{O}_{2}$ displayed decreased binding of RUNX3 to the RBS1 and RBS2 sites (Figs. 3B and 3C).

ROS regulate the Akt1/ $\beta$-catenin signaling pathway. There are many reports that ROS regulate cell survival by modulating the Akt signaling pathway $(24,25)$. Treatment of SNU-407 cells with $\mathrm{H}_{2} \mathrm{O}_{2}$ induced $\beta$-catenin expression and GSK-3 $\beta$ phosphorylation (Fig. 4A). A previous study demonstrated that RUNX3 reduces the nuclear localization, transactivation, and stability of $\beta$-catenin protein (23); therefore, we examined the effect of ROS on the expression and localization of endogenous $\beta$-catenin in SNU-407 cells using immunoblot
A

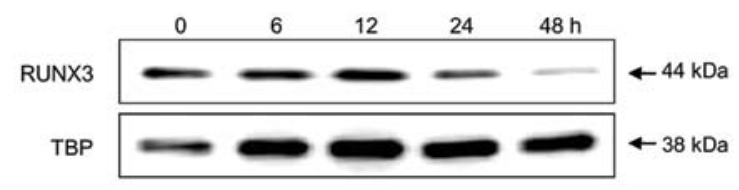

B

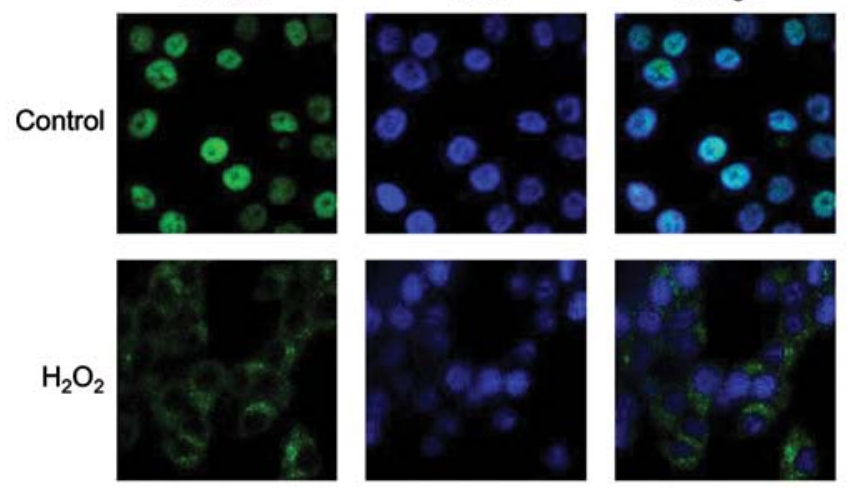

C
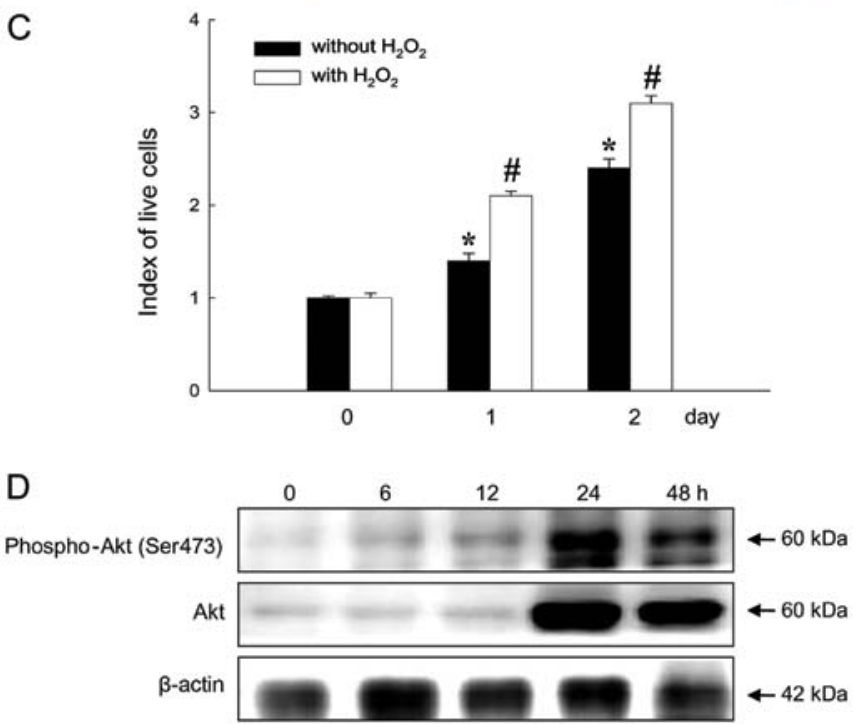

Figure 1. ROS downregulate RUNX3 expression and upregulate Akt expression in SNU-407 cells. Cells were incubated with $100 \mu \mathrm{M} \mathrm{H}_{2} \mathrm{O}_{2}$ for up to $48 \mathrm{~h}$. (A) Nuclear extracts prepared at the indicated times were electrophorised and the cell lysates were immunoblotted using an anti-RUNX3 antibody. TATA box-binding protein (TBP) was used as a loading control. (B) Confocal image showing the location of RUNX3 (green) in control SNU-407 cells and cells treated with $\mathrm{H}_{2} \mathrm{O}_{2}$. DAPI staining (blue) indicates the location of the nucleus and the merged image indicates the nuclear location of RUNX3 protein. (C) Cell proliferation was measured using a trypan blue assay. Cells were counted 0,24 , and $48 \mathrm{~h}$ after treatment of SNU-407 cells with $\mathrm{H}_{2} \mathrm{O}_{2}$. "Significantly different from cells without $\mathrm{H}_{2} \mathrm{O}_{2}$ treatment at day $0(\mathrm{P}<0.05)$; "significantly different from cells with $\mathrm{H}_{2} \mathrm{O}_{2}$ treatment at day $0(\mathrm{P}<0.05)$. (D) Immunoblot analysis of the levels of total Akt and phosphorylated Akt (Phospho-Akt) in cells treated with $\mathrm{H}_{2} \mathrm{O}_{2}$ for up to $48 \mathrm{~h}$. $\beta$-actin was used as a loading control.

and immunocytochemical analyses. Levels of $\beta$-catenin in the nucleus were dramatically higher in $\mathrm{H}_{2} \mathrm{O}_{2}$-treated cells than in control cells (Fig. 4B and 4C), indicating that ROS induce the expression and nuclear localization of $\beta$-catenin in RUNX3-positive cells.

ROS regulate the $\beta$-catenin-mediated induction of cyclin D1. Cyclin D1 is a downstream effector of the Akt $1 / \beta$-catenin 


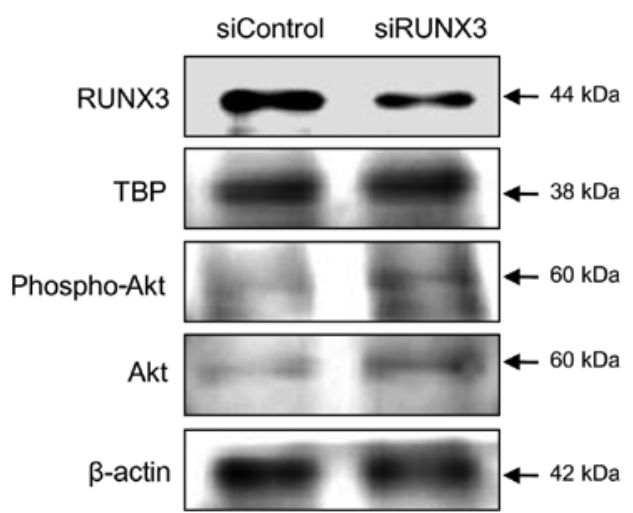

Figure 2. Downregulation of RUNX3 induces Akt protein expression. Immunoblot showing the expression levels of RUNX3, phosphorylated Akt (Phospho-Akt), and total Akt protein after SNU-407 cells were transiently transfected with control or RUNX3-specific siRNA. TBP and $\beta$-actin were used as loading controls.

A

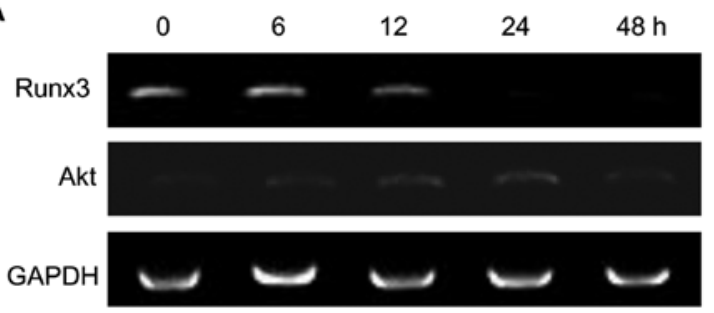

B

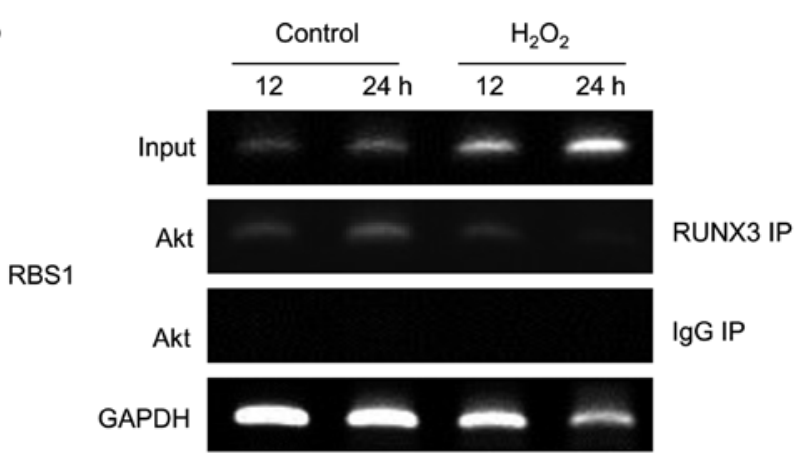

C

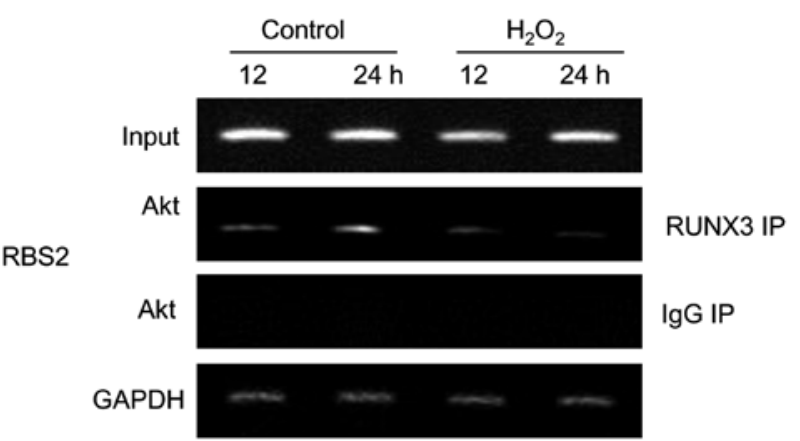

Figure 3. ROS reverse RUNX3-mediated repression of Akt transcription. SNU-407 cells were treated with $100 \mu \mathrm{M} \mathrm{H}_{2} \mathrm{O}_{2}$ for $0,6,12,24$, or $48 \mathrm{~h}$. (A) RT-PCR analysis of the expression levels of RUNX3 and Akt mRNAs following $\mathrm{H}_{2} \mathrm{O}_{2}$ treatment. Expression of GAPDH was measured as a loading control. (B and C) ChIP analysis of the interaction between RUNX3 and Akt was performed using an anti-RUNX3 antibody and primers targeting the Akt promoter region. The intensity of the bands indicates the level of RUNX3 protein bound to the RSB1 (B) and RSB2 (C) sites in the Akt promoter. As a negative control, immunoprecipitation was performed using IgG. Input represents amplification of total DNA from whole cell lysates.

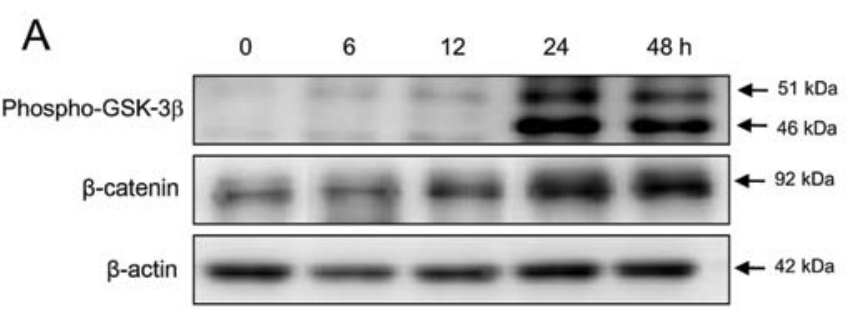

B

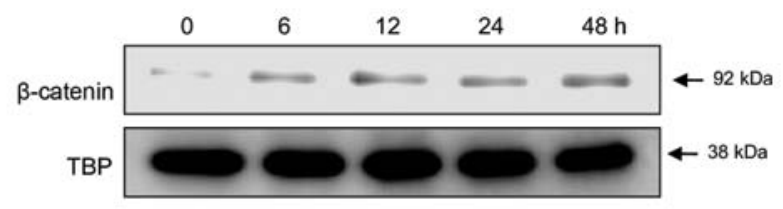

C

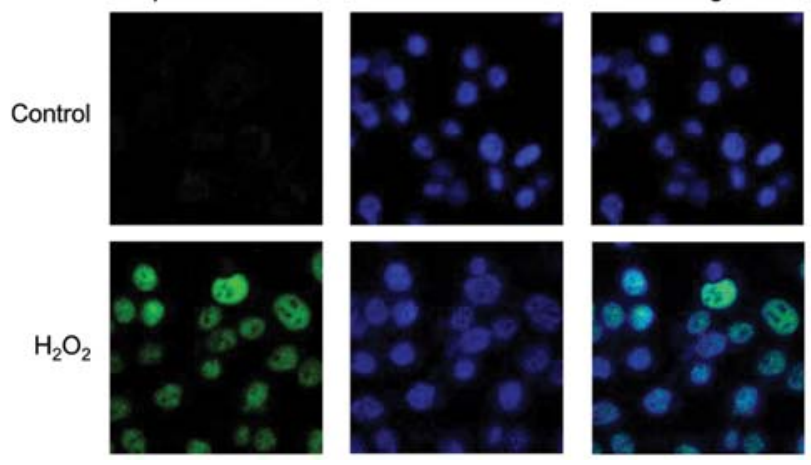

Figure 4. ROS regulate the Akt1/ $\beta$-catenin signaling pathway. (A) Immunoblot of SNU-407 cells treated with $\mathrm{H}_{2} \mathrm{O}_{2}$ for up to $48 \mathrm{~h}$. The levels of $\beta$-catenin and phosphorylated GSK-3 $\beta$ (Phospho-GSK-3 $\beta$ ) protein were increased following the oxidative stress-inducing treatment. $\beta$-actin was used as a loading control. (B) Immunoblot of the expression of $\beta$-catenin in nuclear extracts from $\mathrm{H}_{2} \mathrm{O}_{2}$-treated cells. TBP was used as a loading control. (C) Representative images of $\beta$-catenin (green) expression in control cells and cells treated with $\mathrm{H}_{2} \mathrm{O}_{2}$. DAPI staining (blue) indicates the location of the nucleus and the merged image indicates the nuclear location of RUNX3 protein.

signaling pathway that preferentially binds to and activates CDK4 and CDK6 at G1 phase to initiate cell cycle progression $(26,27)$. Therefore, the effects of ROS on the expression of cyclin D1 and its associated signaling molecules were examined. The cyclin D1 promoter contains adjacent TCF/ LEF (at $-81 \mathrm{bp}$ ) and CREB (at $-58 \mathrm{bp}$ ) binding sites (28). To determine whether ROS induce cyclin D1 via their effects on $\beta$-catenin, ChIP assays were used to investigate the interaction of $\beta$-catenin with the cyclin D1 promoter. Exposure of SNU-407 cells to $\mathrm{H}_{2} \mathrm{O}_{2}$ for $48 \mathrm{~h}$ increased the amount of cyclin D1 promoter DNA that co-immunoprecipitated with $\beta$-catenin (Fig. 5A), indicating that ROS initiate the recruitment of $\beta$-catenin to the cyclin D1 promoter. Exposure of the cells to $\mathrm{H}_{2} \mathrm{O}_{2}$ also increased $\beta$-catenin-mediated cyclin D1 protein expression in a time-dependent manner (Fig. 5B). Taken together, these results indicate that ROS silence RUNX3 expression and activate the Akt1/ $\beta$-catenin/cyclin D1 signaling pathway, which promotes tumorigenesis in colorectal cancer. 
A

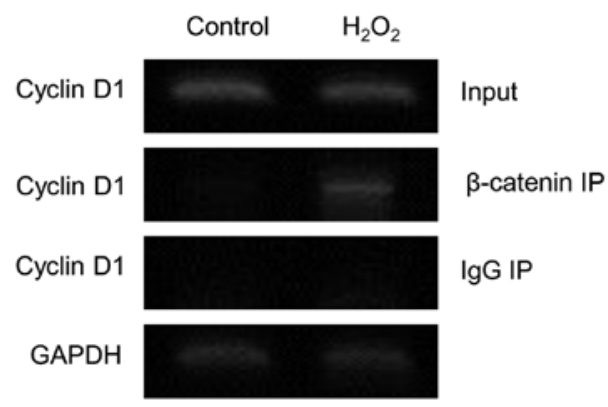

B

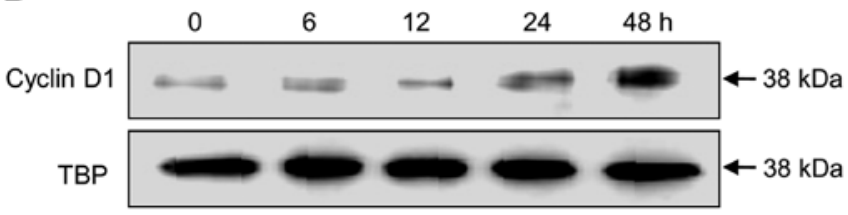

Figure 5. ROS regulate the induction of $\beta$-catenin-mediated cyclin D1 expression. Cells were treated with $100 \mu \mathrm{M} \mathrm{H}_{2} \mathrm{O}_{2}$ for $48 \mathrm{~h}$. (A) ChIP analysis of the direct binding of $\beta$-catenin to the cyclin D1 promoter in SNU-407 cells. Immunoprecipitates were prepared using an anti- $\beta$-catenin antibody or IgG as a control and co-immunoprecipitated DNA was PCR-amplified using cyclin D1-specific primers. The expression of GAPDH was measured as a control. (B) Immunoblot analysis of the expression of cyclin D1 in cells treated with $\mathrm{H}_{2} \mathrm{O}_{2}$ for up to $48 \mathrm{~h}$. Nuclear extracts were electrophoresed and the cell lysates were immunoblotted using an anti-cyclin D1 antibody or an anti-TBP antibody as a control.

\section{Discussion}

An imbalance in the production or removal of ROS can be either directly or indirectly involved in the initiation, promotion, and progression phases of carcinogenesis (29). The generation of ROS is involved in the Akt signaling pathway $(30,31)$ and Akt may foster tumorigenesis in multiple ways $(32,33)$. For example, Akt stabilizes Myc and cyclin D1 and induces degradation of the CDK inhibitor $\mathrm{p} 27$, all of which promote cell cycle progression (34).

This study demonstrates that ROS repress RUNX3 and induce Akt expression and the subsequent GSK-3 $\beta / \beta$-catenin/ cyclin D1 cascade. Knockdown of endogenous RUNX3 in SNU-407 cells increased the expression and phosphorylation of Akt, as well as cell proliferation. The ROS-induced upregulation of Akt and $\beta$-catenin led to the induction of cyclin D1 expression. Therefore, we conclude that downregulation of RUNX3 by ROS leads to activation of the Akt signaling pathway in colorectal cancer.

Over-activation of Akt in cancer cells often occurs as the result of chromosome deletion, genetic mutation, or amplification of the genes that can regulate the activity of Akt. In fact, deletion of the PTEN gene (35) and mutation of the gene encoding phosphoinositide-3-kinase, catalytic, alpha polypeptide have been associated with over-activation of Akt (36). However, the occurrence of genetic alterations of Akt itself is relatively low in gastric cancer (37). Recent studies demonstrate that $\beta$-catenin/TCF/LEF, STAT3, and CREB regulate the activity of the Akt 1 promoter $(38,39)$. In addition, binding sites for AP1, Sp1, and NF- $\mathrm{KB}$ in the Akt 1 promoter have been predicted by software screening (39).
The tumor suppressor RUNX3 is frequently inactivated in gastric cancer tissues (14) and its aberrant activity is closely related to metastatic outcome (40). It has been postulated that the mechanism for RUNX3 inactivation in cancer cells and tissues involves hypermethylation of its promoter region $(14,41)$. The RUNX3 gene is located on human chromosome 1p36 (14), a region containing many genes that play roles in the maintenance of chromosome stability, suppression of tumorigenesis, control of apoptosis, and DNA methylation (42). Deletions in the 1p36 region are common in colorectal cancers (42-45), suggesting that gene loss in this region affects chromosome stability (43). RUNX3 interacts with $\mathrm{mSin} 3$ and Groucho/TLE, which associate with histone deacetylases and SUV39H1, a histone methyltransferase, to inhibit or silence gene transcription (46). The two RUNX3binding sites in the Akt promoter are adjacent to STAT3-binding motifs and $\beta$-catenin/TCF-binding elements. It is possible that binding of RUNX3 to this region blocks the ability of other transcriptional activators to bind to the Akt promoter. RUNX3 can interact with the $\beta$-catenin/TCF complex and this interaction reduces its ability to promote the transcription of target genes in colorectal cancer (47). In this study, we demonstrated that $\beta$-catenin is activated by ROS; however, we were not able to investigate the possibility that RUNX3 interacts with the $\beta$-catenin/TCF complex before binding to the Akt promoter, leading to the inhibition of Akt transcription. Further studies are required to investigate the association between RUNX3 and $\beta$-catenin during tumorigenesis of colorectal cancer.

Taken together, the data presented here suggest that oxidative stress may play an important role in inhibiting the activation of the tumor suppressor RUNX3 and the subsequent regulation of the Akt/ $\beta$-catenin/cyclin D1 cascade in human colorectal cancer cells. This effect of ROS may be associated with the progression of colorectal cancer.

\section{Acknowledgements}

This study was supported by a grant from the National R\&D Program for Cancer Control, Ministry for Health and Welfare, Republic of Korea (1120340).

\section{References}

1. Shibutani $S$, Takeshita $M$ and Grollman AP: Insertion of specific bases during DNA synthesis past the oxidation-damaged base 8-oxodG. Nature 349: 431-434, 1991

2. Hussain SP, Hofseth LJ and Harris CC: Radical causes of cancer. Nat Rev Cancer 3: 276-285, 2003.

3. Gasche C, Chang CL, Rhees J, Goel A, et al: Oxidative stress increases frameshift mutations in human colorectal cancer cells. Cancer Res 61: 7444-7448, 2001.

4. Zienolddiny S, Ryberg D and Haugen A: Induction of microsatellite mutations by oxidative agents in human lung cancer cell lines. Carcinogenesis 21: 1521-1526, 2000.

5. Markowitz S, Wang J, Myeroff L, et al: Inactivation of the type II TGF-beta receptor in colon cancer cells with microsatellite instability. Science 268: 1336-1338, 1995

6. Sugimura T and Ushijima T: Genetic and epigenetic alterations in carcinogenesis. Mutat Res 462: 235-246, 2000.

7. Lim SO, Gu JM, Kim MS, et al: Epigenetic changes induced by reactive oxygen species in hepatocellular carcinoma: methylation of the E-cadherin promoter. Gastroenterology 135: 2128-2140, 2008.

8. Kang KA, Zhang R, Kim GY, Bae SC, et al: Epigenetic changes induced by oxidative stress in colorectal cancer cells: methylation of tumor suppressor RUNX3. Tumour Biol 33: 403-412, 2012. 
9. Lovatt $\mathrm{M}$ and Bijlmakers MJ: Stabilisation of beta-catenin downstream of T cell receptor signalling. PLoS One 5: e12794, 2010.

10. McManus EJ, Sakamoto K, Armit LJ, et al: Role that phosphorylation of GSK3 plays in insulin and Wnt signalling defined by knockin analysis. EMBO J 24: 1571-1583, 2005.

11. Fuchs SY, Ougolkov AV, Spiegelman VS and Minamoto T: Oncogenic beta-catenin signaling networks in colorectal cancer. Cell Cycle 4: 1522-1539, 2005.

12. Bae SC and Choi JK: Tumor suppressor activity of RUNX3. Oncogene 23: 4336-4340, 2004.

13. Subramaniam MM, Chan JY, Yeoh GK, et al: Molecular pathology of RUNX3 in human carcinogenesis. Biochim Biophys Acta 1796: 315-331, 2009.

14. Li QL, Ito K, Sakakura C, et al: Causal relationship between the loss of RUNX3 expression and gastric cancer. Cell 109: 113-124, 2002.

15. Chuang LS and Ito Y: RUNX3 is multifunctional in carcinogenesis of multiple solid tumors. Oncogene 29: 2605-2615, 2010.

16. Chi XZ, Yang JO, Lee KY, et al: RUNX3 suppresses gastric epithelial cell growth by inducing p21(WAF1/Cip1) expression. Mol Cell Biol 25: 8097-8107, 2005.

17. Yano T, Ito K, Fukamachi H, et al: The RUNX3 tumor suppressor upregulates Bim in gastric epithelial cells undergoing transforming growth factor beta-induced apoptosis. Mol Cell Biol 26 4474-4488, 2006.

18. Chang TL, Ito K, Ko TK, et al: Claudin-1 has tumor suppressive activity and is a direct target of RUNX3 in gastric epithelia cells. Gastroenterology 138: 255-265, 2010.

19. Blau S, Rubistein A, Bass P, et al: Differences in the reducing power along the rat GI tract: lower antioxidant capacity of the colon. Mol Cell Biochem 194: 185-191, 1999.

20. Benhar M, Engelberg D and Levitzki A: ROS, stress-activated kinases and stress-signaling in cancer. EMBO Rep 3: 420-425, 2002.

21. Skrzydlewska E, Sulkowski S, Koda M, et al: Lipid peroxidation and antioxidant status in colorectal cancer. World J Gastroenterol 11: 403-406, 2005.

22. Chen JC, Huang KC and Lin WW: HMG-CoA reductase inhibitors upregulate heme oxygenase-1 expression in murine RAW264.7 macrophages via ERK, p38 MAPK and protein kinase G pathways. Cell Signal 18: 32-39, 2006.

23. Lin FC, Liu YP, Lai CH, et al: RUNX3-mediated transcriptional inhibition of Akt suppresses tumorigenesis of human gastric cancer cells. Oncogene 31: 4302-4316, 2012.

24. Lee YJ, Jeong HY, Kim YB, et al: Reactive oxygen species and $\mathrm{PI} 3 \mathrm{~K} / \mathrm{Akt}$ signaling play key roles in the induction of $\mathrm{Nrf2}$ driven heme oxygenase-1 expression in sulforaphane-treated human mesothelioma MSTO- $211 \mathrm{H}$ cells. Food Chem Toxicol 50 : 116-123, 2012

25. Irani K: Oxidant signaling in vascular cell growth, death, and survival: a review of the roles of reactive oxygen species in smooth muscle and endothelial cell mitogenic and apoptotic signaling. Circ Res 87: 179-183, 2000

26. Osaki M, Oshimura M and Ito H: PI3K-Akt pathway: its functions and alterations in human cancer. Apoptosis 9: 667-676, 2004.

27. Malumbres $M$ and Barbacid M: Cell cycle, CDKs and cancer: a changing paradigm. Nat Rev Cancer 9: 153-166, 2009.

28. Pradeep A, Sharma C, Sathyanarayana P, et al: Gastrin-mediated activation of cyclin D1 transcription involves beta-catenin and CREB pathways in gastric cancer cells. Oncogene 23: 3689-3699, 2004
29. Kang DH: Oxidative stress, DNA damage, and breast cancer. AACN Clinical Issues 13: 540-549, 2002.

30. Wang X, McCullough KD, Franke TF and Holbrook NJ: Epidermal growth factor receptor-dependent Akt activation by oxidative stress enhances cell survival. J Biol Chem 275: 14624-14631, 2000.

31. Huang C, Li J, Ding M, et al: UV Induces phosphorylation of protein kinase B (Akt) at Ser-473 and Thr-308 in mouse epidermal $\mathrm{Cl} 41$ cells through hydrogen peroxide. J Biol Chem 276: 40234-40240, 2001.

32. Manning BD and Cantley LC: AKT/PKB signaling: navigating downstream. Cell 129: 1261-1274, 2007.

33. Plas DR and Thompson CB: Akt-dependent transformation: there is more to growth than just surviving. Oncogene 24: 7435-7442, 2005.

34. Los M, Maddika S, Erb B and Schulze-Osthoff K: Switching Akt: from survival signaling to deadly response. Bioessays 31 : 492-495, 2009.

35. Oki E, Baba H, Tokunaga $\mathrm{E}$, et al: Akt phosphorylation associates with $\mathrm{LOH}$ of PTEN and leads to chemoresistance for gastric cancer. Int J Cancer 117: 376-380, 2005.

36. Li VS, Wong CW, Chan TL, et al: Mutations of PIK3CA in gastric adenocarcinoma. BMC Cancer 5: 29, 2005.

37. Soung YH, Lee JW, Nam SW, et al: Mutational analysis of AKT1, AKT2 and AKT3 genes in common human carcinomas. Oncology 70: 285-289, 2006.

38. Dihlmann S, Kloor M, Fallsehr C and von Knebel Doeberitz M: Regulation of AKT1 expression by beta-catenin/Tcf/Lef signaling in colorectal cancer cells. Carcinogenesis 26: $1503-1512,2005$.

39. Misra UK and Pizzo SV: Upregulation of AKT1 protein expression in forskolin-stimulated macrophage: evidence from ChIP analysis that CREB binds to and activates the AKT1 promoter. J Cell Biochem 100: 1022-1033, 2007.

40. Fahrner JA, Eguchi S, Herman JG and Baylin SB: Dependence of histone modifications and gene expression on DNA hypermethylation in cancer. Cancer Res 62: 7213-7218, 2002.

41. Li QL, Kim HR, Kim WJ, et al: Transcriptional silencing of the RUNX3 gene by CpG hypermethylation is associated with lung cancer. Biochem Biophys Res Commun 314: 223-228, 2004

42. Di Vinci A, Infusini E, Nigro S, et al: Intratumor distribution of $1 p$ deletions in human colorectal adenocarcinoma is commonly homogeneous: indirect evidence of early involvement in colorectal tumorigenesis. Cancer 83: 415-422, 1998.

43. Di Vinci A, Infusini E, Peveri C, et al: Correlation between $1 \mathrm{p}$ deletions and aneusomy in human colorectal adenomas. Int $\mathrm{J}$ Cancer 75: 45-50, 1998.

44. Tanaka K, Yanoshita R, Konishi M, et al: Suppression of tumourigenicity in human colon carcinoma cells by introduction of normal chromosome 1p36 region. Oncogene 8: 2253-2258, 1993.

45. Praml C, Finke LH, Herfarth C, et al: Deletion mapping defines different regions in 1p34.2-pter that may harbor genetic information related to human colorectal cancer. Oncogene 11: 1357-1362, 1995.

46. Durst KL and Hiebert SW: Role of RUNX family members in transcriptional repression and gene silencing. Oncogene 23: 4220-4224, 2004.

47. Ito Y: RUNX genes in development and cancer: regulation of viral gene expression and the discovery of RUNX family genes. Adv Cancer Res 99: 33-76, 2008. 